\title{
Overweight and Obesity in Saudi Adults with Type 1 Diabetes Mellitus
}

\author{
Khalid S Aljabri ${ }^{1}$, Samia A Bokhari ${ }^{1}$, Muneera A Alshareef ${ }^{1}$, Patan M Khan ${ }^{1}$ and Bandari K Aljabri ${ }^{2}$ \\ ${ }^{1}$ Department of Endocrinology, King Fahad Armed Forces Hospital, Jeddah, Kingdom of Saudi Arabia \\ ${ }^{2}$ College of medicine, Um Al Qura University, Makkah, Kingdom of Saudi Arabia
}

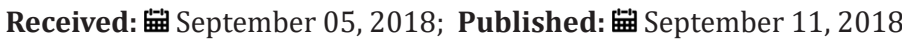

*Corresponding author: Khalid SJ Aljabri, Department of Endocrinology, King Fahad Armed Forces Hospital, Jeddah, Kingdom of Saudi Arabia

\section{Abstract}

Background: Worldwide epidemic exists with respect to diabetes mellitus, primarily because of increased rates of obesity. The trend of increasing obesity prevalence has increased at a faster rate in patients with T1DM compared to the general population.

Methods: This cross-sectional study was conducted at Primary Health Care Clinics and the diabetes centre at King Fahad Armed Forces Hospital. A total of 237 Saudi with T1DM and 238 non diabtic patients (control) were randomly selected.

Result: A total of 475 patients attending the Primary Health Care Clinics and the diabetes centre were included in this study; 193 (40.6\%) were male, $282(59.4 \%)$ were female with mean age $27.6 \pm 2.9$ years. T1DM group comprised of 237 (49.9\%) patients and non-diabetic (control) group comprised of 238 (50.1\% ) of the sample. T1DM patients were not significantly different in age, had significant higher BM and HbA1c values when compared to control subjects. A comparison between both diabetic and control groups in relation to BMI subgroups and in relation to gender revealed that T1DM with BMI $\geq 30(138(56.6 \%))$ were significantly more frequent than control cases $(106(43.3 \%)), P=0.003$. However, Overweight and obesity were more frequent in female patients, there were no significant difference between gender. Obesity was significantly more frequent in female T1DM compared to control cases $(76.1 \%$ vs $23.9 \%)$ with female to male ratio $3.2: 1.0, \mathrm{p}=0.03$.

Conclusion: Patients with T1DM develop overweight and obesity more frequently than the general population. Gender-related differences in body weight in young type 1 diabetic adults were observed. The study stress that T1DM patients require special attention. This can be done through health education at the primary care level and the diabetic clinics.

\section{Introduction}

Diabetes mellitus is the third greatest cause of death all over the world and is responsible for many complications affecting various organs in the body. Patients with type 1 diabetes mellitus (T1DM) constitute about $5-10 \%$ of all cases of diabetes. The incidence of T1DM continues to rapidly increase from $2.8 \%$ to $3.2 \%$ in various populations globally [1-3]. In Saudi Arabia, studies indicate a significant increase in incidence rates of T1DM in groups older than 12 years [4,5]. Saudi Arabia is eighth on a list of top 10 countries for number of children diagnosed per year, just after the United Kingdom [6]. A nationwide Saudi Arabian project was conducted in the years 2001-2007,45,682 children and adolescents were surveyed. Fifty children and adolescents were identified to have T1DM with a prevalence rate of 109.5 per 100,000 [6]. In the last few decades,

an epidemic of overweight and obesity has been observed in the general population of most western countries and Saudi Arabia [710]. Some studies have shown that this epidemic could also affect individuals with T1DM. A patient with T1DM has been traditionally described as having normal body weight and a patient with type 2 diabetes as overweight or obese; however, nowadays, phenotypic changes occur and overweight and obesity have become much more common among T1DM patients [11-13]. The trend of increasing obesity prevalence has increased at a faster rate in patients with T1DM compared to the general population [11]. Currently, around $50 \%$ of patients with T1DM are either overweight or obese. They also have higher waist and hip circumferences when compared to healthy controls [13]. In the Pittsburgh Epidemiology of Diabetes Complications Study, which followed adult patients with T1DM for 
an average of 18 years, prevalence of overweight increased from 29 to $42 \%$ and prevalence of obesity increased sevenfold from 3 to $23 \%$ [11]. Weight gain appeared to be unrelated to aging and instead related to clinical factors such as insulin therapy [11]. Comorbidities, often associated with excess body weight, reduce the benefits of good metabolic control [14]. Thus, controlling body weight in patients with T1DM is necessary due to the well-known relationship between obesity and cardiovascular disease [15]. Metabolic abnormalities related to obesity are likely to modify cardiovascular disease risk in this population and complications related to cardiovascular disease have been the leading cause of mortality in patients with T1DM $[15,16]$. The aim of this study was to evaluate the frequency of overweight and obesity in young adults with T1DM and in healthy controls.

\section{Methods}

This cross sectional study was conducted at Primary Health Care Clinics and the diabetes centre at King Fahad Armed Forces Hospital. A total of 237 Saudi with T1DM and 238 non-diabtic patients (control) were randomly selected. The demographic data and medical history were documented. The Body mass index (BMI) was considered normal if it was below $25 \mathrm{~kg} / \mathrm{m} 2,25-29.9 \mathrm{~kg} / \mathrm{m} 2$ overweight and $30 \mathrm{~kg} / \mathrm{m} 2$ or greater was obese [17]. Glycosylated hemoglobin (HbA1c) was measured using the high-performance liquid chromatography.

\section{Statistical Analysis}

Univariate analysis of baseline and follow up demography and clinical laboratory endpoints were accomplished using unpaired t-test. Chi square(X2) test were used for categorical data comparison. Pearson's correlations between continuous variables were used as a measure of association. All statistical analyses. were performed using SPSS Version 22.0. All P values were based on twosided tests. $\mathrm{P}<0.05$ was considered significant.

\section{Results}

The essential physical data of the total cohort and difference between the diabetic patients and controls are listed in Table 1. A total of 475 patients attending the Primary Health Care Clinics and the diabetes centre were included in this study;193 (40.6\%) were male, 282 (59.4\%) were female with mean age $27.6 \pm 2.9$ years. T1DM group comprised of 237 (49.9\%) patients and non-diabetic (control) group comprised of 238 (50.1\%) of the sample. T1DM patients were not significantly different in age, had significant higher BMI and HbA1c values when compared to control subjects. Figure 1 shows a comparison between both T1DM and control groups in relation to BMI subgroups and in relation to gender. T1DM with BMI $\geq 30$ (138(56.6\%)) were significantly more frequent than control cases (106(43.3\%)), $\mathrm{P}=0.003$. However, Overweight and obesity were more frequent in female patients, there were no significant difference between gender, figure. Obesity was significantly more frequent in female T1DM compared to control cases $(76.1 \%$ vs $23.9 \%$, respectively) with female to male ratio $3.2: 1.0, \mathrm{p}=0.03$.

Table 1: Demographic patients' parameters and Comparison of features between Type 1 diabetes and control.

\begin{tabular}{|c|c|c|c|c|}
\hline \multirow{2}{*}{ Parameters } & \multicolumn{2}{|c|}{$\begin{array}{c}\text { Type 1 diabetes 237 } \\
\text { (49.9) }\end{array}$} & $\begin{array}{c}\text { Control 238 } \\
\text { (50.1) }\end{array}$ & \multirow{2}{*}{ P value } \\
\hline \multirow{2}{*}{ Gender } & Male & $70(36.3)$ & $123(63.7)$ & \multirow{2}{*}{$<0.0001$} \\
\cline { 2 - 5 } & Female & $167(59.2)$ & $115(40.8)$ & \\
\hline \multicolumn{2}{|r|}{ Age(years) } & $27.5 \pm 1.4$ & $27.7 \pm 3.9$ & 0.5 \\
\hline \multicolumn{2}{|c|}{ Body mass index $\left(\mathrm{kg} / \mathrm{m}^{2}\right)$} & $31.7 \pm 5.9$ & $30.2 \pm 6.0$ & 0.007 \\
\hline \multicolumn{2}{|c|}{ HbA1c } & $7.7 \pm 2.2$ & $5.7 \pm 0.4$ & $<0.0001$ \\
\hline
\end{tabular}
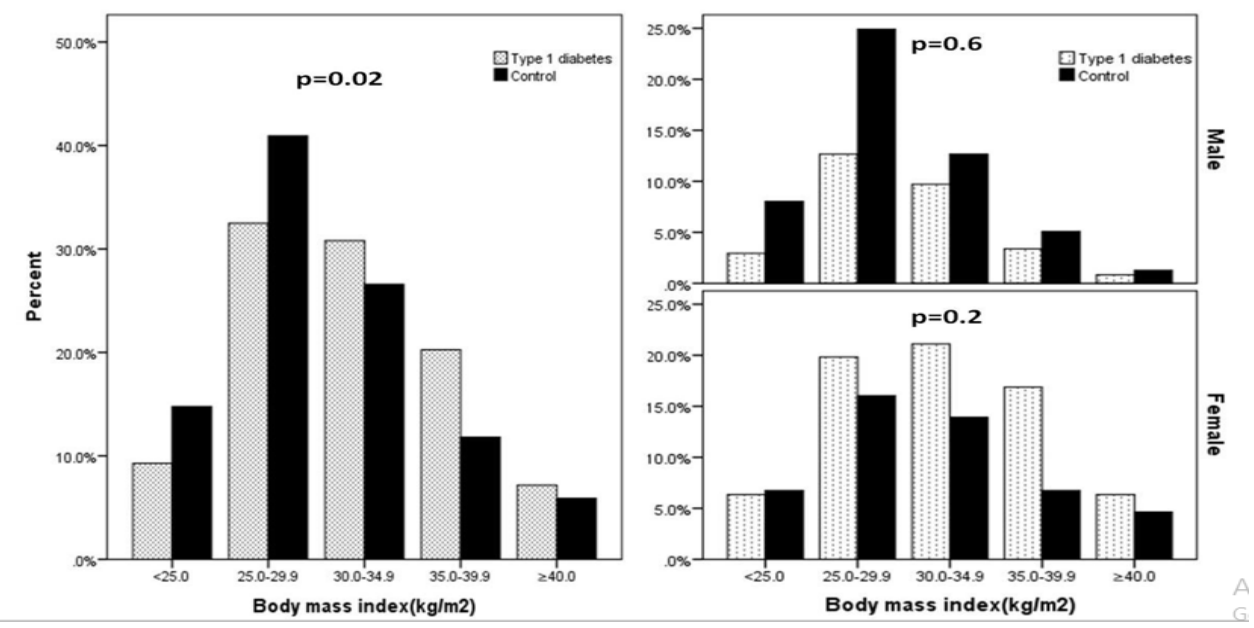

Figure 1: Frequency of Type 1 diabetes and control cases with body mass index groups and gender.

\section{Discussion}

This study highlights the importance of overweight and obesity in Saudi T1DM population. Patients with T1DM constitute about
$5-10 \%$ of all cases of diabetes. Both women and men with T1DM have increased cardiovascular and all-cause mortality compared to persons without T1DM, and the risk for premature death is increasing with increasing HbA1c levels [18]. An important 
observation was that T1DM patients have higher BMI compared to nondiabetic cases. This signifies individuals having T1DM associated obesity might be more prone to develop cardiovascular disease than obese non-diabetic individuals. Obesity is a severe public health problem. It is a major determinant of many noncommunicable diseases, including type 2 diabetes mellitus and coronary heart disease $[7,19]$. Obesity is a very expensive disease that causes a great loss of quality of life and suffering, not only to the patients but also to the families $[20,21]$. In the past 20 years, the prevalence of obesity has tripled worldwide, to the extent that it is now being considered an epidemic [22]. Obesity, defined as a body mass index (BMI) of $\geq 30 \mathrm{~kg} / \mathrm{m} 2$, affects approximately $35 \%$ of men and $40 \%$ of women in the USA [23]. It has recently been reported that obesity in particular is rising at a greater rate than overweight [24]. The prevalence of obesity in adults is $10 \%$ to $25 \%$ in most countries of western Europe and $20 \%$ to $25 \%$ in some countries of the Americas [7]. Nationally, studies demonstrated a prevalence of $21-31 \%$ [8-10]. The present work shows that overweight and obesity were more common among females than males in both children and adults [8-10,25,26]. The presented study revealed that adult patients with type 1 diabetes were more frequently overweight and obese than their healthy peers. The prevalence of overweight and obesity in the control group, corresponds with Polish data which indicates that the control group can be considered representative of the general population. Though patients with T1DM have traditionally been thought to have lower BMI, other research has shown otherwise [31,27]. The trend of increasing obesity prevalence has increased at a faster rate in patients with T1DM compared to the general population. $11 \mathrm{We}$ found over weight and obesity were present in $36.7 \%$ and $51.4 \%$ of patients with T1DM respectively. Currently, around $50 \%$ of patients with T1DM are either overweight or obese. and between 20 and 40\% meet the criteria of metabolic syndrome, depending on the study population and the diagnostic criteria used [28]. They also have higher waist and hip circumferences when compared to healthy controls [13]. In the Pittsburgh Epidemiology of Diabetes Complications Study, which followed adult patients with T1DM for an average of 18 years, prevalence of overweight increased from 29 to $42 \%$ and prevalence of obesity increased sevenfold from 3 to $23 \%$ [11]. Weight gain appeared to be unrelated to aging and instead related to clinical factors such as insulin therapy [11]. Double diabetes is a new term used to describe patients with T1DM who also show clinical signs of type 2 diabetes such as obesity and insulin resistance $[29,30]$. With the rising rates of overweight and obesity among patients with T1DM, there are no longer clear divisions between the two major diabetes subtypes except at time of diagnosis, as the disease appears to behave as a continuum with the two components of its etiology, insulin deficiency, and insulin resistance [29]. Obesity and insulin resistance may accelerate development of T1DM in young predisposed individuals [31-33]. Increasing insulin dosage due to insulin resistance can lead to further weight gain, thus exacerbating the weight problem [34]. Double diabetes is a cyclical mechanism of weight gain and insulin resistance that should be recognized and treated early. Patients with T1DM who are overweight or obese are at a greater risk of developing double diabetes due to their significantly elevated levels of osteopontin [35]. Osteopontin is a sialoprotein associated with normal physiological processes as well as autoimmune disease and has been demonstrated to induce adipose tissue inflammation, increase pro-inflammatory cytokine release, and promote development of insulin resistance. 36 Importantly, several studies have shown that obesity and metabolic syndrome in T1DM are associated with the development and progression of micro- and macrovascular complications [36-38].

We found obesity was significantly more frequent in female T1DM compared to male T1DM (76.1\% vs $23.9 \%)$ with female to male ratio $3.2: 1.0, p=0.03$, where as, female control compared to male control cases $(57.5 \%$ vs $42.5 \%$ ) with female to male ratio 1.4:1.0, $\mathrm{p}=0.01$. Subgroup analysis among men and women showed that the higher prevalence of overweight and obesity in diabetic patients in comparison to the control group was restricted to women. A Swedish study showed a similar trend to the presented study; at the age of 18, diabetic girls were heavier and had higher BMI than control girls, which was not observed among boys [39]. Krishnan S et al. [40] also found that female adolescents with type 1 diabetes had more centrally distributed fat. However, the reports from Italy revealed no gender difference, suggesting that the gender differences may be influenced by locally specific factors [41]. The explanation of the tendency to gain weight in T1DM patients is very complex. The increasing prevalence of overweight and obesity may result from the overall trend observed in the general population, from an anabolic effect of insulin treatment, or from a higher caloric intake as a result of fear of hypoglycaemia $[41,42]$. The Diabetes Control and Complications Trial (DCCT) Research Group demonstrated that patients treated with intensive insulin therapy gained an average of $4.6 \mathrm{~kg}$ more than those on conventional therapy during a 5-year follow-up period [43]. Insulin itself promotes weight gain as it stimulates lipogenesis, inhibits protein catabolism, and slows down basal metabolism. These effects are also enhanced by peripheral insulin administration, which is associated with a reduced energy metabolism. In subjects with T1DM, insulin therapy induces insulin resistance selective for carbohydrate metabolism. Consequently, insulin doses need to be increased to maintain glycaemic control but, as insulin maintains its role in lipogenesis and protein metabolism, intensification of insulin treatment promotes fat mass increases and lean body mass gain [44]. The main limitation of our study was the rather small number of obese persons, particularly when gender sub analyses were performed.

\section{Conclusion}

Patients with T1DM develop overweight and obesity more frequently than the general population. Gender-related differences in body weight in young type 1 diabetic adults were observed. The study stress that T1DM patients require special attention. This can 
be done through health education at the primary care level and the diabetic clinics.

\section{References}

1. Gale EAM (2000) The Rise of Childhood Type 1 Diabetes in the 20th Century. Diabetes 51(12): 3353-3361.

2. Green A, Patterson CC (2001) Trends in Incidence in Childhood-Onset Diabetes in Europe 1989-1998. Acta Diabetologica 3: B3-B8.

3. Diamond Project Group (2006) Trends in the Incidence of Childhood Type 1 Diabetes Worldwide 1990-1999. Diabet Med 23(8): 857-866.

4. Alotaibi A, Perry L, Gholizadeh L (2017) Incidence and prevalence rates of diabetes mellitus in Saudi Arabia: An overview. J Epidemiol Glob Health 7(4): 211-218.

5. International Diabetes Federation (2017) IDF Diabetes Atlas, ( $8^{\text {th }}$ edn.), International Diabetes Federation, Brussels, Belgium.

6. Al-Herbish AS, El-Mouzan MI, Al-Salloum AA, Al-Qurachi MM, Al-Omar AA (2008) Prevalence of type 1 diabetes mellitus in Northern Saudi Arabian children and adolescents. Saudi Med J 29(9): 1285-1288.

7. (1997) World Health Organization. Obesity epidemic puts millions at risk from related diseases. WHO/46, Geneva.

8. Al-Rehaimi AA, Bjorntrop P (1992) Obesity and fat distribution in women from Saudi Arabia. Int J Obes Relat Metab Disord 16(12): 10171019.

9. Al-Nuaim AA, Bamgboye EJ, Al-Rubeaan KA, Al-Mazrou Y (1997) Overweight and obesity in Saudi Arabian adult population: role of sociodemographic variables. J Commun Health 22(3): 211-223.

10. Al-Mahross F, Al-Roomi K (1999) Overweight and obesity in the Arabian Peninsula: an overview. J R Soc Health 119(4): 251-253.

11. Conway B, Miller RG, Costacou T, Fried L, Kelsey S, et al. (2010) Temporal patterns in overweight and obesity in Type 1 diabetes. Diabet Med 27(4): 398-404.

12. Nazim J, Starzyk J (2009) Obesity in children and adolescents and diabetes. Przegl Lek 66(1-2): 96-99.

13. Szadkowska A, Madej A, Ziolkowska K, Szymanska M, Jeziorny, K, et al. (2015) Gender and age-dependent effect of type 1 diabetes on obesity and altered body composition in young adults. Ann Agric Environ Med 22(1): 124-128.

14. Chillaron JJ, Benaiges D, Mane L, Pedro-Botet J, Flores Le-Roux JA (2015) Obesity and type 1 diabetes mellitus management. Minerva Endocrinol 40(1): 53-60.

15. De Ferranti SD, de Boer IH, Fonseca V, Fox CS, Golden SH, et al. (2014) Type 1 diabetes mellitus and cardiovascular disease: a scientific statement from the American Heart Association and American Diabetes Association. Diabetes Care 37(10): 2843-2863.

16. Secrest AM, Becker DJ, Kelsey SF, LaPorte RE, Orchard TJ (2010) Causespecific mortality trends in a large population-based cohort with longstanding childhood-onset type 1 diabetes. Diabetes 59(12): 3216-3222.

17. Garrow JS, Webster J (1985) Quetlet's index $\left(\mathrm{W} / \mathrm{H}_{2}\right)$ as a measure of fatness. Int J Obes 9(2): 147-153.

18. Lind M, Svensson A-M, Kosiborod M, Gudbjörnsdottir S, Pivodic A, Wedel $\mathrm{H}$, et al. (2014) Glycemic control and excess mortality in type 1 diabetes. N Engl J Med 371(9): 1972-1982.

19. Hill JO, Melanson EL (1999) Overview of the determinants of overweight and obesity: current evidence and research issues. Med Sci Sports Exerc 31(suppl 11): S515-S521.

20. Kurscheid T, Lauterbach K (1998) The cost implications of obesity for health care and society. Int J Obes Relat Metab Disord 22(suppl 1): S3-S5.
21. Levy E, Levy P, Le Pen C, Basdevant A (1995) The economic cost of obesity: French situation. Int J Obes Relat Metab Disord 19(11): 788792.

22. Kjær IGH, Kolle E, Hansen BH, Anderssen SA, Torstveit MK (2015) Obesity prevalence in Norwegian adults assessed by body mass index, waist circumference and fat mass percentage. Clin Obes 5(4): 211-218.

23. Flegal KM, Kruszon-Moran D, Carroll MD, Fryar CD, Ogden CL (2016) Trends in obesity among adults in the United States, 2005 to 2014. JAMA 315(21): 2284-2291.

24. Ghosh A, Charlton KE, Batterham MJ (2016) Socioeconomic disadvantage and its implications for population health planning of obesity and overweight, using cross-sectional data from general practices from a regional catchment in Australia. BMJ Open 6(5): e010405.

25. Rasheed P, Abou-Hozaifa BM, Khan A (1994) Obesity among young Saudi female adults: a prevalence study on medical and nursing students. Public Health 108(4): 289-294.

26. Kordy MN, El-Gamal FM (1985) A study of pattern of body mass index (BMI) and prevalence of obesity in a Saudi population. Asia Pacific J Public Health 8(2): 59-65.

27. Central Statistical Office. The health status of the Polish population in 2009.

28. Chillaron JJ, Flores Le-Roux JA, Benaiges D, Pedro-Botet J (2014) Type 1 diabetes, metabolic syndrome and cardiovascular risk. Metabolism 63(2): 181-187.

29. Giuffrida FM, Bulcao C, Cobas RA, Negrato CA, Gomes MB, et al. (2016) Double-diabetes in a real-world sample of 2711 individuals: associated with insulin treatment or part of the heterogeneity of type 1 diabetes? Diabetol Metab Syndr 8: 28.

30. Schechter R, Reutrakul S (2015) Management of severe insulin resistance in patients with type 1 diabetes. Current diabetes reports 15(10): 77.

31. Fourlanos S, Narendran P, Byrnes GB, Colman PG, Harrison LC (2004) Insulin resistance is a risk factor for progression to type 1 diabetes. Diabetologia 47(10): 1661-1667.

32. Couper JJ, Beresford S, Hirte C, et al. (2009) Weight gain in early life predicts risk of islet autoimmunity in children with a first-degree relative with type 1 diabetes. Diabetes Care 32(1): 94-99.

33. Franck M, Paquot N, Scheen AJ (2012) Influence of body weight on the natural history of and the therapeutic approaches to type 1 diabetes. Rev Med Liege 67: 461-467.

34. Timar R, Timar B, Degeratu D, Serafinceanu C, Oancea C (2014) Metabolic syndrome, adiponectin and proinflammatory status in patients with type 1 diabetes mellitus. J Int Med Res 42(5): 1131-1138.

35. Gomez-Ambrosi J, Catalan V, Ramirez B, Rodriguez A, Colina I, et al. (2007) Plasma osteopontin levels and expression in adipose tissue are increased in obesity. J Clin Endocrinol Metab 92(9): 3719-3727.

36. Barchetta I, Alessandri C, Bertoccini L, Cimini FA, Taverniti L, et al. (2016) Increased circulating osteopontin levels in adult patients with type 1 diabetes mellitus and association with dysmetabolic profile. European Journal of Endocrinology/European Federation of Endocrine Societies. 174(2): 187-192.

37. De Block CE, De Leeuw IH, Van Gaal LF (2005) Impact of overweight on chronic microvascular complications in type 1 diabetic patients. Diabetes Care 28(7): 1649-1655.

38. Polsky S, Ellis SL (2015) Obesity, insulin resistance, and type 1 diabetes mellitus. Curr Opin Endocrinol Diabetes Obes 22(4): 277-282.

39. Domargard A, Sarnblad S, Kroon M, Karlsson I, Skeppner G, et al. (1999) Increased prevalence of overweight in adolescent girls with type 1 diabetes mellitus. Acta Paediatr 88(11): 1223-1228. 
40. Krishnan S, Fields DA, Copeland KC, Blackett PR, Anderson MP, et al. (2012) Sex differences in cardiovascular disease risk in adolescents with type 1 diabetes. Gend Med 9(4): 251-258.

41. Valerio G, Iafusco D, Zucchini S, Maffeis C (2012) Abdominal adiposity and cardiovascular risk factors in adolescents with type 1 diabetes. Diabetes Res Clin Pract 97(1): 99-104.

42. Russell-Jones D, Khan R (2007) Insulin-associated weight gain in diabetes - causes, effects and coping strategies. Diabetes Obes Metab 9(6): 799-812.
43. Purnell JQ, Zinman B, Brunzell JD (2013) The Effect of Excess Weight Gain With Intensive Diabetes Mellitus Treatment on Cardiovascular Disease Risk Factors and Atherosclerosis in Type 1 Diabetes Mellitus: Results From the Diabetes Control and Complications Trial/Epidemiology of Diabetes Interventions and Complications Study (DCCT/EDIC) Study. Circulation 127(2): 180-187.

44. Nair KS, Halliday D, Garrow JS (1984) Increased energy expenditure in poorly controlled Type 1 (insulin-dependent) diabetic patients. Diabetologia 27(1): 1-16.

\section{(c) Comons Attribution 4.0 License}

To Submit Your Article Click Here: Submit Article

DOI: $10.32474 /$ ADO.2018.01.000115

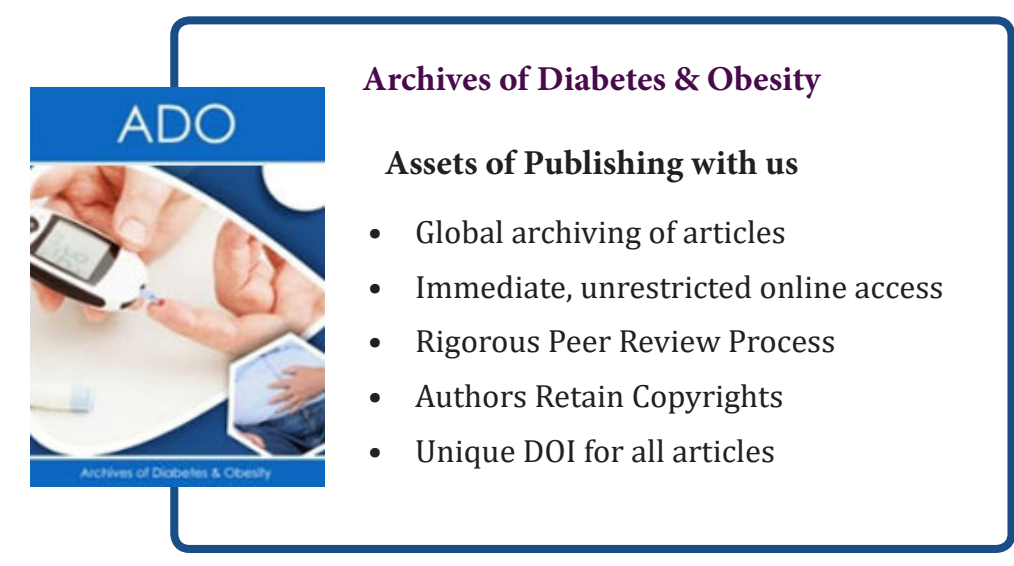

